\title{
Non-cigarette tobacco products: what have we learnt and where are we headed?
}

\author{
Richard J O'Connor
}

\section{Correspondence to} Professor Richard J O'Connor, Associate Professor of Oncology, Department of Health Behavior, Roswell Park Cancer Institute, Elm and Carlton Streets, Buffalo, New York 14263, USA; richard.oconnor@ roswellpark.org

Accepted 20 October 2011

\begin{abstract}
A wide variety of non-cigarette forms of tobacco and nicotine exist, and their use varies regionally and globally. Smoked forms of tobacco such as cigars, bidis, kreteks and waterpipes have high popularity and are often perceived erroneously as less hazardous than cigarettes, when in fact their health burden is similar. Smokeless tobacco products vary widely around the world in form and the health hazards they present, with some clearly toxic forms (eg, in South Asia) and some forms with far fewer hazards (eg, in Sweden). Nicotine delivery systems not directly reliant on tobacco are also emerging (eg, electronic nicotine delivery systems). The presence of such products presents challenges and opportunities for public health. Future regulatory actions such as expansion of smoke-free environments, product health warnings and taxation may serve to increase or decrease the use of non-cigarette forms of tobacco. These regulations may also bring about changes in noncigarette tobacco products themselves that could impact public health by affecting attractiveness and/or toxicity.
\end{abstract}

\section{BACKGROUND}

Tobacco use is projected to kill 1 billion people during the 21st century. While the majority will likely be killed by their use of cigarettes, tobacco use in other forms also contributes to worldwide morbidity and mortality. ${ }^{1}$ Table 1 lists a selection of different classes of non-cigarette forms of tobacco use, including smoked products, smokeless products and also non-tobacco delivery of nicotine. ${ }^{2}$ Such products have historically been treated differently from cigarettes for tax and regulatory purposes, and often have longer histories of use than manufactured cigarettes. All forms of tobacco use have negative health consequences, though the severity of those consequences can vary substantially among products. ${ }^{1}$ There is evidence that some tobacco and nicotine products may pose less of a health hazard than cigarette smoking and so could potentially play a role in reducing morbidity and mortality due to smoking. ${ }^{3}$ However, there is evidence that the public broadly misperceives the relative risks of smoking, tobacco use and nicotine, erroneously thinking smoked tobacco products (eg, waterpipes, cigars, pipes) are less hazardous than cigarettes while believing smokeless forms to be as or more hazardous, and overestimating the health effects due to nicotine. ${ }^{4-8}$

The current paper attempts to describe noncigarette forms of tobacco as threats to and potential opportunities for public health and tobacco control. This paper is not intended to thoroughly review all tobacco product characteristics, their health effects, or usage patterns. Rather, it aims to use recent history to inform where opportunities and challenges for tobacco control and public health may arise.

\section{OVERVIEW OF NON-CIGARETTE TOBACCO PRODUCTS}

Use of other forms of tobacco can be divided into three broad categories: other smoked products, smokeless products and nicotine products. Each will be discussed in turn below.

\section{Smoked tobacco products}

Smoked forms of tobacco other than cigarettes include cigars, pipes, kreteks, bidis and waterpipes. Their use is characterised by the burning of tobacco, and the smoke may be inhaled or may be held in the mouth. In some regions, a phenomenon known as 'reverse smoking' is sometimes observed, wherein the lighted end is placed in the mouth.

\section{Cigars and pipes}

Cigars are traditionally comprised of shredded tobacco wrapped in tobacco leaf, though modern mass-produced products often employ reconstituted tobacco sheet in wrappers. ${ }^{9}$ Subvarieties of cigar vary by size, from cigarette-like little cigars (which often have a filter) to cigarillos to large cigars (which themselves vary tremendously). ${ }^{10}{ }^{11}$ Cigar smoking enjoyed resurgence in the US in the 1990s, particularly among adolescents and those believing it to be less hazardous than cigarettes. ${ }^{9}{ }^{12-16}$ The use of cigars and wrappers (blunts) to administer marijuana and other drugs also has generated concern. ${ }^{17-20}$ Pipes are traditionally composed of a bowl (made of clay or other non-combustible material) where the tobacco is placed for burning, attached to a stem through which the smoke is drawn. The tobaccos used in pipes may sometimes be flavoured. Data on characteristics on cigars and pipes are less commonly available than those for cigarettes. ${ }^{9}{ }^{21-25}$ Rickert and colleagues reported that total particulate matter extracts from cigars and cigarillos were up to $200 \%$ more mutagenic, and pipes $44 \%$ more mutagenic per unit of nicotine, relative to cigarette smoke. ${ }^{24}$ Henningfield et al have shown that cigars differ in $\mathrm{pH}$ levels, which may affect their delivery of nicotine and therefore their abuse potential. ${ }^{25} \mathrm{~A}$ consistent finding of studies examining smoking behaviours and exposures from pipes and cigars is that former cigarette smokers who adopt cigar or pipe use as a harm reduction strategy typically continue to inhale, whereas primary cigar and pipe users generally do not inhale. ${ }^{26-31}$ This is confirmed 
Table 1 Examples of non-cigarette forms of tobacco and nicotine use

\begin{tabular}{lll}
\hline Smoked & Smokeless & Non-tobacco \\
\hline Cigars & Chewing tobacco & Nicotine replacement therapy \\
Pipes & Moist snuff & Electronic nicotine delivery devices \\
Bidis & Dry snuff & \\
Kreteks & Betel quid (with tobacco) & \\
Waterpipes & Gutkha & \\
Cheroot & Toombak & \\
& Dissolvable tobacco & \\
\hline
\end{tabular}

by epidemiological studies, where smokers who have switched to pipes or cigars show little benefit in terms of mortality. ${ }^{32} 33$ Cigar and pipe use are associated with cancers of the mouth, nose and upper airway, ${ }^{32} 34-40$ while cigar use, but not pipe use, appears to be associated with pancreatic cancer. ${ }^{41}$

\section{Bidis and kreteks}

More regionally specific smoked products are bidis and kreteks. Bidis consist of small amounts of tobacco flake and sometimes other flavourants wrapped in a non-tobacco leaf (tendu or temburni) and bound with string. The majority of Indian bidis are hand rolled in a decentralised cottage industry. Kreteks are cigarette-like products originating in Indonesia where tobacco and clove buds are combined with other flavourings before wrapping in paper. The majority of these are machine manufactured in a manner similar to cigarettes. Bidis are the most commonly smoked product in India (even more so than cigarettes), while kretek smokers are more prevalent than 'white cigarette' smokers in Indonesia. ${ }^{1} 2$ However, both products are also used outside their 'native' regions, including Europe and North America. Studies in the US indicate substantial ever use of bidis and kreteks among adolescents and young adults, though it is often coincident with cigarette smoking and use of other tobacco products and perceived to be less hazardous than cigarettes. ${ }^{42}$ Particular concern has also been expressed about the role of eugenol in the smoke of kreteks, which may act as an anaesthetic in the airways, reducing harshness and making smoke more palatable, particularly to young people. ${ }^{43-45}$ Smoking machine studies find bidis and kreteks to yield high amounts of toxicants. ${ }^{46-50}$ Studies examining smoking behaviours and exposures with bidis and kreteks have shown them to differ little from manufactured cigarettes in terms of smoking patterns, $\mathrm{CO}$ exposure and nicotine delivery. ${ }^{51-53}$ In terms of disease risks, bidi use is strongly associated with mortality, ${ }^{54}$ particularly lung and oral cancers, ${ }^{5-59}$ and tuberculosis. ${ }^{59} 60$ Kretek smoking also shows significant mortality risks, though data are less widely available. ${ }^{61} 62$

\section{Waterpipes}

Another smoked form of tobacco use is waterpipe, known in various regions by names such as shisha, hookah and narghile. ${ }^{63}$ Waterpipes typically employ indirect heating of tobacco (often via charcoal), where smoke generated is passed through a chamber containing water before reaching the user via a hose. ${ }^{63}$ Beginning in the 1990s, waterpipes re-emerged as a popular way to use tobacco. ${ }^{64-67}$ A driver in the growth of waterpipe use may have been the introduction of flavoured maasal tobacco preparations for use in waterpipes and the proliferation of waterpipe cafes. ${ }^{67}$ Waterpipe use appears to have become especially popular among university students, ${ }^{68-72}$ many of whom believe that it is less hazardous than cigarette smoking. ${ }^{73-76}$ Studies of use behaviours indicate intake of smoke orders of magnitude higher than from cigarettes with equivalent nicotine exposure. ${ }^{77-82} \mathrm{~A}$ clear product design and performance issue is the use of charcoal as a heating source, which generates copious amounts of carbon monoxide and polycyclic aromatic hydrocarbons. ${ }^{63} 8384$ The literature on the health effects of waterpipe use is less robust than that for cigarettes or smokeless tobacco, ${ }^{63}$ but indicates that waterpipe use is associated with cancer, heart disease, lung function, infectious diseases and reproductive effects. ${ }^{85-87}$

\section{Smokeless tobacco}

Smokeless tobacco is a broad term encompassing a number of different types of tobacco products used orally or nasally. Among these are chewing tobaccos, dry snuff, moist snuff, Swedish-style snus, betel quid, guthka, zarda, toombak and newer dissolvable tobacco products. ${ }^{88}$ A number of other papers have examined the variety of products and their contents. ${ }^{89-94}$ Because the blanket term 'smokeless tobacco' covers such a wide gamut of products, explaining epidemiological associations between ST use and health becomes complicated. Smokeless tobacco as used in Sweden may be linked to pancreatic cancer ${ }^{9596}$ and cardiovascular disease, ${ }^{97} 98$ but does not appear to be associated with other cancers. ${ }^{95} 99100$ In North America, use of chewing tobacco and moist snuff is associated with oral cancer, as well as cancers at other sites, and cardiovascular disease. $^{88100}$ For smokeless products as used in South Asia, there is substantial and consistent evidence for oral cancer and other health effects. ${ }^{88} 101102$ There is also evidence that forms of ST have adverse effects in pregnancy, including preterm delivery. ${ }^{85}$ Many of the observed differences in disease effects may be due to the composition of the products. ${ }^{103}$ Stanfill and colleagues examined variation in smokeless products worldwide, finding that tobacco-specific nitrosamine levels varied by several orders of magnitude (ranging from 4.5 to $516000 \mathrm{ng} / \mathrm{g}$ ). ${ }^{89}$ Even within the US moist snuff market, data show variations in tobaccospecific nitrosamine content up to 18-fold among leading products. ${ }^{90}$ Another knotty terminological issue is the adoption of the Swedish word 'snus' by multinational tobacco manufacturers (eg, Philip Morris, RJ Reynolds, British American Tobacco (BAT)) to describe their newer smokeless products; some of the newer products called 'snus' do not share key characteristics with the snus sold in Sweden, such as nicotine delivery. ${ }^{104}$

\section{ST and harm reduction}

Beginning in the 2000s, data from Sweden emerged suggesting the use of snus may have contributed to declines in cancer and smoking rates. ${ }^{105-109}$ However, this interpretation remains controversial as it is unclear the extent to which circumstances in Sweden would generalise to other markets, such as Europe or Australia, where sale of smokeless tobacco is currently banned or to the US where smokeless containing more toxins has long been available. ${ }^{110-113}$ Nonetheless, these data have formed the basis for movements to promote snus-type products (herein referred to as low nitrosamine smokeless tobacco (LNST)) more broadly as alternatives to cigarettes for smokers. ${ }^{114} 115$ The suggestion that smokers be encouraged to move towards another tobacco product has prompted heated debate within the tobacco control community. ${ }^{116-122}$

There is general agreement in the scientific community that the health hazards from LNST are lower than those of cigarette smoking on the individual level of analysis. ${ }^{112}$ The Scientific Committee on Emerging and Newly Identified Health Risks (SCENIHR) notes in its report: 'It is undeniable that for an individual substitution of tobacco smoking by the use of moist snuff would decrease the incidence of tobacco related 
diseases'. ${ }^{112}$ The major source of argument is in projecting the larger public health effects of such promotion; these arguments grow primarily from different approaches to public health ethics. ${ }^{123}$ Two primary concerns emerge about the promotion of LNST for harm reduction in current smokers: (1) encouragement of novices (particularly youth) to adopt ST use (including the more toxic forms) and; (2) dual use of cigarettes and ST. ${ }^{116} 121124$ A commonly expressed concern is that youth may be attracted to smokeless products, but eventually move to cigarette use (ie, ST acts as a 'gateway' to smoking). Evidence for this is mixed: Swedish data generally show low levels of ST-to-cigarette transition, ${ }^{125-127}$ while North American evidence is equivocal, with some studies showing gateway effects, ${ }^{128-130}$ while others do not. ${ }^{131-134}$ Observed gateway effects may themselves be explainable in part by underlying factors predicting use of both types of tobacco. ${ }^{131} 133$ A second concern has been dual use, or contemporaneous use of ST and cigarettes, which could sustain nicotine addiction, delay cessation and contribute to compensatory smoking of the remaining cigarettes smoked. ${ }^{124}$ A related concern is that if smokers turn to ST when they are unable to smoke, the effect of smoking bans on encouraging smoking cessation may diminish. ${ }^{124} 135136$ Data on current patterns of multiple product use are sparse, but indicate that dual users tend to have higher nicotine dependence, though it is unclear whether this is an antecedent or consequence of dual use. ${ }^{135} 136$ Also of interest is that increases in dual use were not seen with implementation of worksite smoking restrictions in the US, despite marketing by ST manufacturers. ${ }^{137} 138$

\section{ST promotion and population health impact}

With respect to population impact, there is some concern about attracting new users with reduced risk products into the overall pool of tobacco users, whose acquired disease risk would then offset the reduced disease burden among smokers. Kozlowski and colleagues have made the conceptual point that for a product with substantial risk reduction relative to cigarettes (say, $>80 \%$ ), the amount of uptake would have to be extraordinarily high to offset the benefit of moving smokers away from cigarettes. ${ }^{139}$ Levy and colleagues, gaining consensus from leading experts, estimated that LNST was $90 \%$ less hazardous than smoking, ${ }^{140}$ and that promoting ST could reduce smoking prevalence by $1-3$ percentage points, with a small increase in overall ST use. ${ }^{141}$ Other attempts to more comprehensively model population effects have come to diverging conclusions. ${ }^{142} 143$ Gartner and colleagues modelled loss in health-adjusted life expectancy for four groups relative to never smokers: continuing smokers, smokers who switch to Swedish snus, smokers who quit and snus users who never smoked. ${ }^{142}$ Life tables based on the Australian population were used, and potential health outcomes associated with smoking were based on the American Cancer Society's Cancer Prevention Study II (CPS-II) and the Australian Burden of Disease Study, while those associated with snus were based on Levy et al, ${ }^{140}$ with modelling estimates derived using Monte Carlo simulation. They found little difference in life expectancy loss between those who quit tobacco altogether and smokers who switched to snus, with both far lower than continued smoking. They also noted that $14-25$ former smokers would have to adopt snus use to offset the health gain of each smoker who switched to snus, and 14-25 never smokers would have to adopt snus to offset the health benefit of each person who initiated snus rather than smoking. ${ }^{142}$ Both of these indicated net public health benefit of snus. Meija and colleagues built their model beginning with non-users and postulating different pathways for initiation and use of cigarettes and smokeless tobacco: never users, initiated ST and initiated cigarettes (these were further subdivided into stable, health concerned, smoke-free environments and price sensitive smokers). ${ }^{143}$ The authors relied on the Levy et al expert estimate of $90 \%$ risk reduction for ST relative to cigarettes, ${ }^{140}$ creating a health effects scale ranging from never smoking (set to 0 ) to exclusive ST use (mean 11) to exclusive smoking (set to 100). Four scenarios for promotion of ST were considered, which were modelled to influence initiation rates, and Monte Carlo simulation used to model a decision tree leading to overall distributions of health effects. They found little evidence that even aggressive promotion of ST would benefit public health in terms of a downward shift in health effects distribution; indeed the ratios of health effects (compared to the base case) ranged from 0.92 to 1.26 , indicating little reduction to slight increase in overall population health impact. ${ }^{143}$ These two modelling exercises demonstrate the complexity in trying to assess the downstream impacts of patterns of individual behaviour on population health.

\section{Non-tobacco nicotine delivery}

Of course, use of tobacco products is not the only way humans can self-administer nicotine. Around the world, nicotinecontaining medications have been approved in several forms: transdermal patches, gum, lozenges, sublingual tablets, inhalers and nasal sprays. (The nicotine in such medications is ultimately derived from tobacco, rather than synthesised in the laboratory.) All of these products have undergone numerous randomised controlled trials and have demonstrated safety and efficacy in increasing the likelihood of cessation. ${ }^{144}$ In most countries, nicotine replacement therapies (NRTs) are approved for brief use (12 weeks) for cessation of smoking, though the UK has recently expanded its indications to assist smokers in reducing their cigarette consumption. ${ }^{145}$ The WHO in 2009 added NRT (patches and gum) to its Essential Medicines list, a testament to its safety and efficacy track record and in recognition of the public health need for efficacious smoking cessation treatments in the context of the Framework Convention on Tobacco Control (FCTC). ${ }^{146}$ A number of authors have made the case for NRTs as harm reduction products for smokers unable or unwilling to quit. ${ }^{139} 147-150$ There is emerging evidence that a substantial minority of NRT use is for reasons other than cessation $^{151} 152$ with little evidence of abuse by non-tobacco users. $^{153} 154$

A broad class of products has also emerged over the last two decades that claim to provide nicotine apart from traditional tobacco or pharmaceutical sources. In the 2000s, for example, several websites began offering nicotine lollipops and lip balms, which were rejected by US regulators as unapproved drugs and abuses of the compounding privilege afforded to pharmacists. ${ }^{155-157}$ A related product concept marketed several times in different forms is bottled water containing nicotine. ${ }^{157}$ Other products have included 'tobacco gel' substitutes for cigarettes, made from tobacco extracts and delivering nicotine transdermally. However, these 'underground' products have tended not to attract much market share.

\section{Electronic nicotine delivery systems (ENDS)}

Electronic nicotine delivery systems (ENDS), however, upset this trend. Emerging in 2006 in China, they became more widely available throughout the world in 2008-2009. ${ }^{158-160}$ These devices, often constructed to resemble cigarettes, work by vapourising a solution containing nicotine dissolved with flavourants in a carrier medium (usually propylene glycol). ${ }^{161}$ The products have typically been promoted as having reduced 
health risk compared to tobacco use and able to be used in situations where smoking is prohibited. The product occupies an interesting place with respect to harm reduction; unlike the case of medicinal nicotine products or even Swedish snus, where data on relative harms are plentiful, data on ENDS are lacking. ${ }^{161}$ On the one hand, nicotine delivered by vapour with few known toxicants should theoretically carry relatively low risks, particularly when compared to cigarettes. ${ }^{162}$ The limited data available suggest that the products are not likely to approach the health hazards of cigarettes. ${ }^{161} 162$ However, on the other hand, significant concerns exist with the purity of ingredients employed, device functionality and quality control, the ease with which devices can be modified by users, and the general lack of oversight in manufacturing or marketing. ${ }^{163}{ }^{164}$ Additionally, the nicotine deliveries of ENDS tested thus far have been significantly lower than that of cigarettes, raising questions of whether they can substitute effectively over the long term. ${ }^{165} 166$ Survey studies with self-selected users indicate that ENDS users have used them to quit smoking cigarettes, but thus far no randomised controlled trials have been published. ${ }^{161} 167168$ ENDS availability and promotion has prompted vociferous debate within the tobacco control community of a level commensurate with that surrounding LNST. 160169

\section{WHAT IS COMING OVER THE NEXT 20 YEARS}

Predicting the future is always difficult. Still, current trends can sometime be instructive in informing where tobacco control might move in the coming decades. Clearly in the last 20 years, the rise of a tobacco control movement with strong moral force coupled to strong science has been instrumental in driving numerous policy changes, such as indoor smoking restriction (predicated on the rights of non-smokers to breathe unpolluted air), advertising bans (reducing the exposure of children to smoking promotion), taxation (providing an economic disincentive for smokers to continue) and education (providing health warnings to smokers and non-smokers alike). Circumstances in the future may provide opportunities for tobacco control to exert these influences on the use of non-cigarette tobacco products in ways that benefit public health.

\section{Impacts of regulatory policy \\ Framework convention on tobacco control}

The FCTC, while ostensibly aiming to reduce the health effects of all forms of tobacco use through policy intervention, has largely focused on the effects and regulation of cigarette smoking. That is, there has been relatively less attention paid to policies that may impact the use of other forms of tobacco. This is especially problematic in markets where manufactured cigarettes do not dominate, such as India. The mere fact of the FCTC and its early focus on cigarette-relevant policies may play a role in shaping the future of non-cigarette tobacco products in the marketplace.

\section{Smoke-free environments}

The implementation guidelines for Article 8 recommend 100\% bans in worksites, restaurants and bars. Movements are now in place to restrict smoking in certain public outdoor spaces as well (eg, parks, beaches, building entryways). This may create market pressures on smokers still addicted to nicotine to seek out alternative delivery systems. Indeed, marketing by tobacco companies targeting new smokeless products towards smokers in the US have taken this approach. ${ }^{170-172}$ Whether these strategies will be expanded to other markets is presently unclear, as the EU and Australia show little sign of lifting their restrictions on snus sales. In addition, some smoking restriction regulations have included exemptions for waterpipe cafes, which may add to their appeal, inasmuch as they can be used indoors and in social situations. ${ }^{173} 174$ The extent to which these current loopholes are closed may do a lot to curtail growing interest in alternative smoked products.

\section{Health warning labels}

The wider adoption of effective pictorial health warnings that depict the hazards of tobacco use (Article 11) will play a crucial role in educating tobacco users, particularly in developing countries. Evidence consistently shows that pictorial health warnings have contributed to increased knowledge of specific health effects of smoking in a number of countries. ${ }^{175-177}$ Health warnings clearly can and should be appropriately and accurately applied to all tobacco products. However, one recent study showed that graphic health warnings on smokeless tobacco products overwhelmed acceptance of a scientifically valid relative health risk message on the packaging and actually increased false beliefs about the relative health effects of ST and cigarettes. ${ }^{178}$ This raises practical considerations for communicating relative risks of products to the public. If one considers pictorial health warnings as a broad system for health education, then one could imagine coordinated warnings across products distinguishing the most from least hazardous by virtue of the health effects displayed (in markets where appropriate). This could serve to simultaneously discourage initiation, encourage cessation, and also make apparent the relative risks of different products. Such an approach could correct the prevalent misperceptions that cigars, waterpipes and other smoked products are less hazardous than cigarettes and also the misperception that LNST is equally or more hazardous, while not explicitly promoting any particular product class.

\section{Product regulation}

Articles 9 and 10 of the FCTC deal most directly with the regulation and disclosure to governments and the public of tobacco product contents and emissions. At the 2010 conference of parties, partial guidelines for these related articles were released. The parties noted that the regulation of tobacco products could help to reduce morbidity and mortality '... by reducing the attractiveness of tobacco products, reducing their addictiveness... or reducing their overall toxicity'. ${ }^{179}$ The specific recommendations relevant to non-cigarette tobacco products are summarised in table 2 . The FCTC envisions broad authority for agencies to begin to constrain the production of tobacco products in various ways. This may mean greater authority in countries such as India, for example, to reduce the variety of smokeless tobacco products by restricting non-tobacco additives (eg, areca nut, herbs and spices). Opportunities exist to obtain more information about tobacco products and to regulate their contents and emissions. Such actions could set an achievable bar for non-cigarette products elsewhere in the world. The Swedish experience shows that oral tobacco products could be made to contain far fewer toxicants than are currently seen in South Asian products and even most North American smokeless products, yet achieve popularity in the market. ${ }^{89}$ The WHO Study Group on Tobacco Product Regulation (TobReg), in a technical report, has laid out reasoning for limits on specific toxicants in smokeless tobacco products, such as nitrosamines and heavy metals, which are technically achievable. ${ }^{180} 181$ AyoYusuf and Connolly point to toxicological principles that could 
Table 2 Selected recommendations regarding regulation and disclosure of tobacco product characteristics and emissions, 4th Conference of the Parties to the Framework Convention on Tobacco Control (FCTC), 2010

\begin{tabular}{ll}
\hline Characteristic & Recommendations \\
\hline Laboratory standards & For purposes of disclosure, testing laboratories \\
& should meet standards for ISO 17025 accreditation \\
& Compliance laboratories should be independent of \\
& the tobacco industry \\
& Consider various means to pay for product \\
& regulatory systems, including dedicated taxes, \\
Financing & licensing fees, product registration fees and \\
& non-compliance levies \\
& Apply appropriate legal frameworks to prevent \\
& unauthorised use and disclosure of information \\
Confidentiality & claimed to be commercially sensitive or confidential \\
& Require manufacturers to disclose actual quantities \\
of ingredients used in manufacture of products by \\
product type and brand style in a standardised format \\
Require manufacturers to disclose the suppliers, types \\
and characteristics of tobacco leaf by product type \\
and brand style (eg, variety of tobacco, reconstituted \\
sheet and/or expanded tobacco use) \\
Require manufacturers to notify authorities of changes \\
to products \\
Require manufacturers to provide a statement of \\
purpose underlying the use of ingredients \\
Regulate or restrict ingredients that may be used \\
increase palatability of tobacco products (eg, \\
cinnamon, mint), create impression of health benefits \\
(eg, vitamins), or are associated with energy or vitality \\
(eg, caffeine) \\
Impose legal responsibilities on manufacturers for \\
compliance and impose penalties for violations \\
Consider sampling products from facilities and retailer \\
outlets for compliance testing \\
Specify appropriate sanctions for non-compliance \\
and ensure authorities have power to seize and \\
destroy non-compliant product and levy penalties
\end{tabular}

help shape the regulation of existing and new ST products, noting that nitrosamines and cadmium were associated with the largest estimated cancer risks. ${ }^{182}$ Thus, the next 20 years could witness the emergence of performance standards for smokeless tobacco products.

The prospects for product-level regulatory action regarding products such as cigars, bidis, kreteks and waterpipe are less clear. Data on the characteristics of other tobacco products besides cigarettes and smokeless tobacco are sparse, and so additional research may be necessary to identify key compounds of health concern before product standards or other productlevel regulations could be promulgated. However, decentralised production and cottage industries such as bidi making may prove a complication in enforcing product standards. Still, the flavoured tobaccos used in waterpipes (maasal) could be targeted by regulators under the recommended guidelines for Articles 9 and 10 dealing with the use of flavourings to increase the attractiveness of tobacco products. Given this appears to have been key to the growth in their popularity, ${ }^{64}{ }^{67}$ limiting or eliminating the use of flavourants may lead to a decline in waterpipe use.

\section{US Food and Drug Administration (FDA)}

While the US has not ratified FCTC, the regulatory authority provided to the US FDA in 2009 provides a mechanism to achieve some of the same ends and may help to create precedents for other countries to follow with respect to product regulation under Articles 9 and 10. The FDA has banned flavoured cigarette products (other than menthol), restricted the use of misleading terms such as 'light' and 'mild', created a registration and reporting system for manufacturers, and instituted retail sales inspections and enforcement. The law also gives the FDA broader powers to shape the tobacco product market for the protection of public health, such as issuance of product standards, requirements for premarket approval for new products, and formal determination of substantial equivalence for product modifications. Since it has only had jurisdiction over tobacco for 2 years, the agency is still defining the boundaries of its authority. The FDA regulations have thus far not been applied to cigars, so while kreteks were nominally banned in the US under FDA legislation (as clove was not a permitted characterising flavour), some have been reintroduced as little cigars. ${ }^{183} \mathrm{~A}$ court decision (Sottera vs FDA) essentially declared ENDS to be tobacco products rather than drugs or medical devices (inasmuch as they are 'made or derived from tobacco' and not making a therapeutic claim), a classification to which the agency acceded. Around the same time, the FDA declared two products (Ariva BDL and Stonewall BDL), which had been submitted for consideration as modified risk tobacco products, to be not tobacco products, a decision apparently driven by undisclosed details in the manufacturing process. ${ }^{184}$ The agency is pursuing rulemaking to bring all products made or derived from tobacco under the same set of premarket and postmarket rules governing cigarettes and smokeless tobacco. ${ }^{185} 186$

The most important opportunities for the FDA to shape tobacco control into the future may be in the setting of performance standards; the premarket process for new or substantially equivalent products; and, separately premarket authorisation of modified exposure/risk claims. Product standards for smokeless tobacco, for example, could restrict the manipulation of $\mathrm{pH}$ and mandate lower concentrations of toxicants (eg, heavy metals, nitrosamines). Clearly, this would be technically achievable; as Hecht and coworkers have pointed out, the technology exists for US smokeless manufacturers to make less toxic products, yet they have not thus far applied it. ${ }^{181}$ Clamoured for by health groups for decades following on the public health disaster of low-tar cigarettes, the FDA will have the opportunity to formally evaluate many tobacco products before they are sold. Required evaluations of substantially equivalent products mean that companies must demonstrate that modifications to their products (relative to a reference product) do not raise health concerns, meaning that product changes would have to be justified on a public health basis, rather than simply on toxicology. Claims for risk or exposure reductions for non-cigarette products as compared to cigarettes would have to be scientifically justified, including evidence that consumers would not be misled by the marketing and that there would be a net public health benefit. It is likely that manufacturers will pursue such claims for LNST and possibly dissolvable tobacco and ENDS. Whether and how many such claims are permitted will depend on how the agency sets the evidentiary standard. The Tobacco Products Scientific Advisory Committee (TPSAC) is currently charged with producing a report on the public health effects of dissolvable tobacco products (eg, Ariva), and a committee of the Institute of Medicine is considering scientific standards for studies of modified risk tobacco products, so this is an active and evolving area. It is clear, however, that providing a firm evidence base to guide regulatory decision making will become increasingly important.

\section{Taxation}

Tax policies also have potential for shaping the development of the tobacco market. Taxation has effectively been used around 
the world as a means to reduce cigarette consumption; in general, a $10 \%$ increase in price brings about a $1 \%$ decrease in smoking prevalence. However, this effect can be influenced by affordability of the product; that is, its 'real price' in the context of income growth and inflation. ${ }^{187}$ Two types of taxes can be applied: specific (a fixed amount per some unit) or ad valorem (proportional to value). In general, specific taxes are more advantageous than ad valorem taxes to companies making premium-priced brands, ${ }^{187}$ since they tend to enhance price differentials.

Taxes can vary significantly for non-cigarette tobacco products. Cigar and pipe tobacco taxes are typically based on weight, and vary from jurisdiction to jurisdiction. In the US, smokeless tobacco is subject to specific and ad valorem taxes; at the federal level, a specific (weight-based) tax is used, while in most states an ad valorem tax is applied. ${ }^{188}$ Rates vary widely from $100 \%$ of wholesale price in Wisconsin to no tax at all in Pennsylvania. In India, cigarettes are taxed at rate over 60 times higher than that for bidis, while throughout the Middle East waterpipe tobacco is taxed at ad valorem rates ranging from $2 \%$ in Libya to $108 \%$ in Lebanon. ${ }^{187}$ Clearly, then, there is wide variability in the tax treatment of non-cigarette tobacco products. Thus far, in markets where they are permitted, ENDS have not been subject to tobacco taxes.

Loopholes and complexities in tobacco tax structures, as well as crossborder differences in price, create incentives for tax avoidance. ${ }^{187}$ Consumers with the means to do so will tend to seek out cheaper products or cheaper sources of product, such as using discount brands, switching to other tobacco products, or travelling to locations where prices/taxes are lower. ${ }^{189}$ Manufacturers can also alter or reposition their products to take advantage of tax loopholes. Little cigars emerged partially in response to the tax differential between cigarettes and cigars at the state and federal level. ${ }^{11}$ Following a 2009 Federal excise tax increase in the US that largely equalised taxes between cigarettes and little cigars, some manufacturers added weight to their 'little cigars' so that they would qualify as less-taxed 'large cigars' ${ }^{190}$ And, other manufacturers reclassified their rolling tobacco as 'pipe tobacco' for similar tax reasons, resulting in a sudden increase in pipe tobacco sales. ${ }^{191}$

Consumers, when faced with price differentials, may substitute a related product for the desired one, for example, discount and roll-your-own (RYO) cigarettes for premium ones. ${ }^{189}$ This can also extend to non-cigarette tobacco products, though the economics for these products are not as well studied. A key question in this context is the cross-price elasticity, or the change in consumption of the substitute that occurs with an increase in the price of cigarettes. ${ }^{187}$ If this is positive, then the products are substitutes, while if it is negative, the products are complements. Some have suggested taking advantage of this substitution behaviour by setting tax structures to incentivise smokers to adopt less hazardous forms of tobacco/nicotine use. ${ }^{115} 147$ Others argue that all tobacco products should be taxed consistently (eg, a comparable share of price) so as to reduce potential for substitution as a method of tax avoidance, discourage initiation and encourage cessation of all products. ${ }^{188} 192$ Which is the preferable approach may depend on the specifics of the available products and regulatory conditions. In the US, where the FDA can formally evaluate modified risk/ exposure claims, there may be opportunities to provide tax advantages to products that are authorised to make such claims as a way to draw users away from more hazardous products (eg, tax exempt or low tax relative to other products).
Could non-cigarette tobacco or nicotine products attract new markets?

The dominance of the cigarette may be wavering in certain markets, even as cigarette manufacturers enter new markets. Clearly, waterpipes are growing in popularity worldwide, fed by attractive flavours, imagery and perceptions of safety. ${ }^{67}$ BAT, Swedish Match, RJ Reynolds and Philip Morris believe at least some smokers may be attracted to smokeless tobacco. ${ }^{172} 193$ They have acquired smokeless tobacco manufacturers and/or introduced smokeless tobacco products, often linked to established cigarette brand names. Historical context also suggests that populations can shift with regard to their preferred delivery systems for nicotine. ${ }^{194} 195$ Use of chewing and snuffing tobacco products was impacted by anti-spitting laws enacted in the late 1800s and early 1900s to combat the spread of tuberculosis and other infectious diseases. ${ }^{194}$ Smoked products then became acceptable substitutes. A century later, the pendulum appears to be swinging in the opposite direction, particularly as the health hazards of passive smoking were established. Cigarette smoking is becoming a stigmatised behaviour as prevalence declines and restrictions proliferate. ${ }^{196-199}$ Since smokeless tobacco use, particularly in its spitless forms, is less visible to others, it may carry less social stigma than does smoking. Medicinal nicotine and ENDS may have similar advantages vis a vis social acceptability. So, social pressures being applied to cigarette use could contribute to making non-cigarette tobacco relatively more attractive to those addicted to nicotine. And as noted earlier, increasing cigarette taxes (and therefore prices) may make substitution of less taxed tobacco products evermore economically attractive so long as product differentials in tax treatment persist.

An interesting case study to watch is how ENDS have achieved notoriety. ENDS have spread via the internet ${ }^{159160}$ and pressure groups and trade associations created to promote them. ${ }^{200}$ A community of users ('vapers') has emerged, facilitated by the internet and social networking, arguing forcefully for light regulation, if any, for the product (eg, Consumer Advocates for Smoke-free Alternatives Association). Message boards (eg, Vapor Talk Forum) allow users to exchange experiences, as well as to obtain information about modifying ENDS and sharing 'how to' instructions. The ease of peer-to-peer communication facilitated by the internet may allow novel product use to diffuse more widely than by traditional channels. ${ }^{201}$ Peer-to-peer communication can be an effective form of persuasion. If one considers a 'diffusion of innovations' framework, this makes perfect sense; early adopters are often highly influential in driving new product use and popularising niche products. $^{202}$ The ENDS issue may reflect broader trends in social networking and the promotion of tobacco products. Internal documents indicate that R.J. Reynolds explored viral strategies to market its Eclipse reduced risk cigarette, ${ }^{203}$ and there is evidence that tobacco companies have been directly and indirectly marketing via social media. ${ }^{204-206}$ Message boards for Camel Snus showed that participants advised one another on product use, purchase locations and suggestions on improving the product. ${ }^{206}$ These developments may have implications for how research findings and regulatory actions regarding tobacco products are communicated and understood in the 21 st century. That is, scientists and public health advocates may increasingly have to rely on alternative strategies to disseminate information into the public sphere, complementing the traditional outlets of journal publications and government reports. ${ }^{207}$ Translating knowledge to regulators and the public, who will increasingly 


\section{What is already known on this topic}

All forms of tobacco use have negative health consequences, though the severity of those consequences can vary substantially among products.

\section{What this paper adds}

Over the next 20 years, increased regulation and social disapproval of cigarette smoking may increase the attractiveness of non cigarette tobacco and nicotine products. This represents both a challenge and opportunity for public health and tobacco control.

communicate among themselves, may require much more direct and 'real-time' engagement by tobacco control scientists.

\section{CONCLUSIONS AND RESEARCH AGENDA}

A wide variety of non-cigarette forms of tobacco and nicotine exist, ranging from smoked forms to smokeless forms to tobacco-free nicotine. Non-cigarette forms of tobacco are widely available, and their use varies regionally and globally. Smoked forms of tobacco such as bidis, kreteks and waterpipes have high popularity and are often perceived erroneously as less hazardous than cigarettes, when in fact their health burden is similar. Smokeless tobacco products vary widely around the world in form and associtated health hazards, with some clearly toxic forms (eg, in South Asia), and some forms with far fewer hazards (eg, in Sweden). A market is also burgeoning for nicotine delivery systems not directly reliant on tobacco (eg, ENDS). Broadly, while there is a continuum of risk for tobacco products, public perceptions and indeed regulatory schemes do not often coincide with actual risk. ${ }^{1-3}$ Regulations under the FCTC and the US FDA may occasion a shift away from cigarettes towards other forms of tobacco use, and these regulations may also bring about changes in non-cigarette tobacco products themselves that could impact public health by reducing attractiveness and/or toxicity.

Research needs in tobacco control may shift if non-cigarette tobacco products grow in popularity around the world. It will be important to make sure that independent science is available to guide governments in making evidence based decisions, as it has for the past 20 years of tobacco control activity. Below is a list of priority areas where greater research effort could be directed:

- More thorough characterisation of non-cigarette tobacco products in terms of composition and toxicity to inform regulators developing reporting guidelines.

- Modelling contributions of non-cigarette tobacco product use to overall morbidity and mortality, in particular modelling replacement of cigarette smoking by other forms of tobacco/nicotine use.

- Development of appropriate health warning messages and pictorials for non-cigarette tobacco products.

- Effects of product standards for various smokeless tobacco products on individual and population health.

- Effects of policy interventions that discourage cigarette use on the use of other tobacco products.
- Impacts of social media and social networks on the diffusion of non-cigarette tobacco use.

Acknowledgements Thanks to Kaila Norton for editorial assistance.

Funding RJO is supported by research grants and contracts from the US National Cancer Institute.

Competing interests RJO has served as a consultant to the WHO and to the US Food and Drug Administration regarding tobacco product regulation, and serves on a committee of the Institute of Medicine charged with recommending scientific standards for studies of modified risk tobacco products.

Provenance and peer review Commissioned; externally peer reviewed.

\section{REFERENCES}

1. Tobacco Free Initiative. Tobacco: Deadly in Any Form or Disguise. Geneva: World Health Organization, 2006. http://www.who.int/tobacco/communications/events/ wntd/2006/Tfi Rapport.pdf (accessed 25 Mar 2011).

2. Prignot JJ, Sasco AJ, Poulet E, et al. Alternative forms of tobacco use. Int $\mathrm{J}$ Tuberc Lung Dis 2008;12:718-27.

3. Le Houezec J, McNeill A, Britton J. Tobacco, nicotine and harm reduction. Drug Alcohol Rev 2011;30:119-23.

4. Cummings KM, Hyland A, Giovino GA, et al. Are smokers adequately informed about the health risks of smoking and medicinal nicotine? Nicotine Tob Res 2004;6 (Suppl 3):S333-40.

5. Smith SY, Curbow B, Stillman FA. Harm perception of nicotine products in college freshmen. Nicotine Tob Res 2007:9:977-82.

6. Shiffman S, Ferguson SG, Rohay J, et al. Perceived safety and efficacy of nicotine replacement therapies among US smokers and ex-smokers: relationship with use and compliance. Addiction 2008;103:1371-8.

7. Bansal MA, Cummings KM, Hyland A, et al. Stop-smoking medications: who uses them, who misuses them, and who is misinformed about them? Nicotine Tob Res 2004;6(Suppl 3):S303-10.

8. O'Connor RJ, McNeill A, Borland R, et al. Smokers' beliefs about the relative safety of other tobacco products: findings from the ITC collaboration. Nicotine Tob Res 2007;9:1033-42.

9. National Cancer Institute. Cigars: Health Effects and Trends. Smoking and Tobacco Control Monograph 9. Bethesda: National Cancer Institute, 1998.

10. Kozlowski LT, Dollar KM, Giovino GA. Cigar/cigarillo surveillance: limitations of the U.S. Department of Agriculture system. Am J Prev Med 2008:34:424-6.

11. Delnevo CD, Hrywna M. "A whole 'nother smoke" or a cigarette in disguise: how RJ Reynolds reframed the image of little cigars. Am J Public Health 2007:97:1368-75.

12. Centers for Disease Control and Prevention (CDC). Cigar smoking among teenagers-United States, Massachusetts, and New York, 1996. MMWR Morb Mortal Wkly Rep 1997:46:433-40.

13. Nyman AL, Taylor TM, Biener L. Trends in cigar smoking and perceptions of health risks among Massachusetts adults. Tob Control 2002;11(Suppl 2):ii25-8.

14. Gilpin EA, Pierce JP. Cigar smoking in California: 1990-1996. Am J Prev Med 1999;16:195-201.

15. Delnevo CD. Smokers' choice: what explains the steady growth of cigar use in the U.S.? Public Health Rep 2006;121:116-19.

16. Soldz S, Huyser DJ, Dorsey E. The cigar as a drug delivery device: youth use of blunts. Addiction 2003;98:1379-86.

17. Baker F, Dye JT, Denniston MM, et al. Risk perception and cigar smoking behavior. Am J Health Behav 2001;25:106-14.

18. Delnevo CD, Hrywna M. The relationship of cigars, marijuana, and blunts to adolescent bidi use. Public Health Rep 2006;121:603-8.

19. Sifaneck SJ, Johnson BD, Dunlap E. Cigars-for-blunts: choice of tobacco products by blunt smokers. J Ethn Subst Abuse 2005;4:23-42.

20. Golub $\mathbf{A}$, Johnson $\mathrm{BD}$, Dunlap $\mathrm{E}$. The growth in marijuana use among American youths during the 1990s and the extent of blunt smoking. J Ethn Subst Abuse 2005; $4: 1-21$.

21. Rickert WS, Robinson JC, Bray DF, et al. Characterization of tobacco products: a comparative study of the tar, nicotine, and carbon monoxide yields of cigars, manufactured cigarettes, and cigarettes made from fine-cut tobacco. Prev Med 1985;14:226-33.

22. Appel BR, Guirguis G, Kim IS, et al. Benzene, benzo(a)pyrene, and lead in smoke from tobacco products other than cigarettes. Am J Public Health 1990;80:560-4.

23. Hoffmann D, Wynder EL. Smoke of cigarettes and little cigars: an analytical comparison. Science 1972;178:1197-9.

24. Rickert WS, Wright WG, Trivedi AH, et al. A comparative study of the mutagenicity of various types of tobacco products. Regul Toxicol Pharmacol 2007; 48:320-30.

25. Henningfield JE, Fant RV, Radzius $\mathrm{A}$, et al. Nicotine concentration, smoke pH and whole tobacco aqueous $\mathrm{pH}$ of some cigar brands and types popular in the United States. Nicotine Tob Res 1999;1:163-8.

26. Rodriguez J, Jiang R, Johnson WC, et al. The association of pipe and cigar use with cotinine levels, lung function, and airflow obstruction: a cross-sectional study. Ann Intern Med 2010;152:201-10. 
27. Funck-Brentano C, Raphaël $\mathrm{M}$, Lafontaine $\mathrm{M}$, et al. Effects of type of smoking (pipe, cigars or cigarettes) on biological indices of tobacco exposure and toxicity. Lung Cancer 2006:54:11-18.

28. Pechacek TF, Folsom AR, de Gaudermaris R, et al. Smoke exposure in pipe and cigar smokers. Serum thiocyanate measures. JAMA 1985;254:3330-2.

29. Turner JA, Sillett RW, McNicol MW. Effect of cigar smoking on carboxyhaemoglobin and plasma nicotine concentrations in primary pipe and cigar smokers and ex-cigarette smokers. Br Med J 1977;2:1387-9.

30. Turner JA, Sillett RW, McNicol MW. The inhaling habits of pipe smokers. Br J Dis Chest 1981;75:71-6.

31. Goldman AL. Carboxyhemoglobin levels in primary and secondary cigar and pipe smokers. Chest 1977:72:33-5.

32. Baker F, Ainsworth SR, Dye JT, et al. Health risks associated with cigar smoking JAMA 2000;284:735-40.

33. Wald NJ, Watt HC. Prospective study of effect of switching from cigarettes to pipes or cigars on mortality from three smoking related diseases. $B M J$ 1997:314:1860-3.

34. McCormack VA, Agudo A, Dahm CC, et al. Cigar and pipe smoking and cancer risk in the European Prospective Investigation into Cancer and Nutrition (EPIC). Int J Cancer 2010;127:2402-11.

35. Boffetta $\mathbf{P}$, Pershagen $\mathrm{G}$, Jöckel $\mathrm{KH}$, et al. Cigar and pipe smoking and lung cancer risk: a multicenter study from Europe. J Natl Cancer Inst 1999;91:697-701.

36. Shapiro JA, Jacobs EJ, Thun MJ. Cigar smoking in men and risk of death from tobacco-related cancers. J Natl Cancer Inst 2000;92:333-7.

37. Iribarren C, Tekawa IS, Sidney $\mathrm{S}$, et al. Effect of cigar smoking on the risk of cardiovascular disease, chronic obstructive pulmonary disease, and cancer in men. N Engl J Med 1999;340:1773-80.

38. Tverdal A, Bjartveit K. Health consequences of pipe versus cigarette smoking. Tob Control 2011:20:123-30

39. Henley SJ, Thun MJ, Chao A, et al. Association between exclusive pipe smoking and mortality from cancer and other diseases. J Natl Cancer Inst 2004; 96 :853-61

40. Shaper AG, Wannamethee SG, Walker M. Pipe and cigar smoking and major cardiovascular events, cancer incidence and all-cause mortality in middle-aged British men. Int J Epidemiol 2003;32:802-8.

41. Bertuccio P, La Vecchia C, Silverman DT, et al. Cigar and pipe smoking, smokeless tobacco use and pancreatic cancer: an analysis from the International Pancreatic Cancer Case-Control Consortium (PanC4). Ann Oncol 2011;22:1420-6.

42. Hrywna M, Delnevo CD, Pevzner ES, et al. Correlates of bidi use among youth Am J Health Behav 2004;28:173-9.

43. Guidotti TL, Laing L, Prakash UB. Clove cigarettes. The basis for concern regarding health effects. West J Med 1989:151:220-8.

44. Guidotti TL, Laing L. Clove cigarettes. West J Med 1992;156:537-8.

45. American Medical Association Council on Scientific Affairs. Evaluation of the health hazard of clove cigarettes. JAMA 1988;260:3641-4.

46. Polzin GM, Stanfill SB, Brown CR, et al. Determination of eugenol, anethole, and coumarin in the mainstream cigarette smoke of Indonesian clove cigarettes. Food Chem Toxicol 2007:45:1948-53.

47. Stanfill SB, Brown CR, Yan XJ, et al. Quantification of flavor-related compounds in the unburned contents of bidi and clove cigarettes. J Agric Food Chem 2006;54:8580-8

48. Stanfill SB, Calafat AM, Brown CR, et al. Concentrations of nine alkenylbenzenes, coumarin, piperonal and pulegone in Indian bidi cigarette tobacco. Food Chem Toxicol 2003;41:303-17.

49. Watson CH, Polzin GM, Calafat AM, et al. Determination of tar, nicotine, and carbon monoxide yields in the smoke of bidi cigarettes. Nicotine Tob Res 2003;5:747-53

50. Wu W, Song S, Ashley DL, et al. Assessment of tobacco-specific nitrosamines in the tobacco and mainstream smoke of bidi cigarettes. Carcinogenesis 2004;25:283-7.

51. Malson JL, Lee EM, Murty $\mathrm{R}$, et al. Clove cigarette smoking: biochemical, physiological, and subjective effects. Pharmacol Biochem Behav 2003;74:739-45.

52. Kumar R, Prakash S, Kushwah AS, et al. Breath carbon monoxide concentration in cigarette and bidi smokers in India. Indian J Chest Dis Allied Sci 2010;52:19-24.

53. Behera D, Dash S, Dinakar M. Correlation of smoking behaviour and blood carboxyhaemoglobin in bidi and cigarette smokers. Indian J Chest Dis Allied Sci 1991;33:43-6.

54. Gupta PC, Asma S, eds. Bidi Smoking and Public Health. New Delhi: Ministry of Health and Family Welfare, Government of India, 2008.

55. Pednekar MS, Gupta PC, Yeole BB, et al. Association of tobacco habits, including bidi smoking, with overall and site-specific cancer incidence: results from the Mumbai cohort study. Cancer Causes Control 2011:22:859-68.

56. Prasad R, Ahuja RC, Singhal S, et al. A case-control study of bidi smoking and bronchogenic carcinoma. Ann Thorac Med 2010;5:238-41.

57. Prasad R, Singhal S, Garg R. Bidi smoking and lung cancer. Biosci Trends 2009;3:41-3.

58. Jayalekshmy PA, Akiba S, Nair MK, et al. Bidi smoking and lung cancer incidence among males in Karunagappally cohort in Kerala, India. Int $\mathrm{J}$ Cancer 2008;123:1390-7.

59. Gajalakshmi V, Peto R, Kanaka TS, et al. Smoking and mortality from tuberculosis and other diseases in India: retrospective study of 43000 adult male deaths and 35000 controls. Lancet 2003;362:507-15.
60. Pednekar MS, Gupta PC. Prospective study of smoking and tuberculosis in India. Prev Med 2007;44:496-8.

61. Suryanto E. Merokok \& Kanker Paru [Smoking and Lung Cancer] (In Indonesian). Thesis. Jakarta, Indonesia: Department of Pulmonology, Faculty of Medicine, University of Indonesia, 1988

62. Situmeang T. Hubungan Merokok Krete Dengan Kanker Paru [The Relation Between Kretek Cigarette and Lung Cancer] (In Indonesian). Thesis. Jakarta, Indonesia: Department of Pulmonology, Faculty of Medicine, University of Indonesia, 2000.

63. Study Group on Tobacco Product Regulation. Waterpipe Tobacco Smoking: Health Effects, Research Needs and Recommended Actions by Regulators. Geneva: World Health Organization, 2005

64. Maziak W. The global epidemic of waterpipe smoking. Addict Behav 2011;36:1-5.

65. Maziak W. The waterpipe: time for action. Addiction 2008;103:1763-7.

66. Maziak W, Ward KD, Afifi Soweid RA, et al. Tobacco smoking using a waterpipe: a re-emerging strain in a global epidemic. Tob Control 2004;13:327-33.

67. Rastam S, Ward KD, Eissenberg T, et al. Estimating the beginning of the waterpipe epidemic in Syria. BMC Public Health 2004;4:32.

68. Eissenberg T, Ward KD, Smith-Simone $S$, et al. Waterpipe tobacco smoking on a U.S College campus: prevalence and correlates. J Adolesc Health 2008:42:526-9.

69. Sutfin EL, McCoy TP, Reboussin BA, et al. Prevalence and correlates of waterpipe tobacco smoking by college students in North Carolina. Drug Alcohol Depend 2011:115:131-6.

70. Jackson D, Aveyard P. Waterpipe smoking in students: prevalence, risk factors symptoms of addiction, and smoke intake. Evidence from one British university. BMC Public Health 2008:8:174

71. Jawaid A, Zafar AM, Rehman TU, et al. Knowledge, attitudes and practice of university students regarding waterpipe smoking in Pakistan. Int J Tuberc Lung Dis 2008;12:1077-84

72. Maziak W, Fouad FM, Asfar T, et al. Prevalence and characteristics of narghile smoking among university students in Syria. Int J Tuberc Lung Dis 2004:8:882-9.

73. Primack BA, Sidani J, Agarwal AA, et al. Prevalence of and associations with waterpipe tobacco smoking among U.S. university students. Ann Behav Med 2008;36:81-6.

74. Roskin J, Aveyard P. Canadian and English students' beliefs about waterpipe smoking: a qualitative study. BMC Public Health 2009:9:10.

75. Smith-Simone S, Maziak W, Ward KD, et al. Waterpipe tobacco smoking knowledge, attitudes, beliefs, and behavior in two U.S. samples. Nicotine Tob Res 2008;10:393-8.

76. Asfar T, Ward KD, Eissenberg T, et al. Comparison of patterns of use, beliefs, and attitudes related to waterpipe between beginning and established smokers. BMC Public Health 2005:5:19.

77. Maziak W, Rastam S, Shihadeh AL, et al. Nicotine exposure in daily waterpipe smokers and its relation to puff topography. Addict Behav 2011;36:397-9.

78. Maziak W, Rastam S, Ibrahim I, et al. CO exposure, puff topography, and subjective effects in waterpipe tobacco smokers. Nicotine Tob Res 2009;11:806-11.

79. Blank MD, Cobb CO, Kilgalen B, et al. Acute effects of waterpipe tobacco smoking a double-blind, placebo-control study. Drug Alcohol Depend 2011;116:102-9.

80. Bacha ZA, Salameh P, Waked M. Saliva cotinine and exhaled carbon monoxide levels in natural environment waterpipe smokers. Inhal Toxicol 2007;19:771-7.

81. Cobb CO, Shihadeh A, Weaver MF, et al. Waterpipe tobacco smoking and cigarette smoking: a direct comparison of toxicant exposure and subjective effects. Nicotine Tob Res 2011;13:78-87.

82. Neergaard J, Singh P, Job J, et al. Waterpipe smoking and nicotine exposure: a review of the current evidence. Nicotine Tob Res 2007:9:987-94.

83. Monzer B, Sepetdjian E, Saliba N, et al. Charcoal emissions as a source of CO and carcinogenic PAH in mainstream narghile waterpipe smoke. Food Chem Toxicol 2008;46:2991-5.

84. Sepetdjian E, Saliba N, Shihadeh A. Carcinogenic PAH in waterpipe charcoal products. Food Chem Toxicol 2010:48:3242-5.

85. England LJ, Kim SY, Tomar SL, et al. Non-cigarette tobacco use among women and adverse pregnancy outcomes. Acta Obstet Gynecol Scand 2010;89:454-64.

86. Akl EA, Gaddam S, Gunukula SK, et al. The effects of waterpipe tobacco smoking on health outcomes: a systematic review. Int J Epidemiol 2010;39:834-57.

87. Raad D, Gaddam S, Schunemann HJ, et al. Effects of waterpipe tobacco smoking on lung function: a systematic review and meta-analysis. Chest 2011:139:764-74.

88. International Agency for Research on Cancer. Smokeless Tobacco and Some Tobacco-Specific N-Nitrosamines. Monograph 89. Lyon: International Agency for Research on Cancer, 2007

89. Stanfill SB, Connolly GN, Zhang L, et al. Global surveillance of oral tobacco products: total nicotine, unionised nicotine and tobacco-specific N-nitrosamines. Tob Control 2011;20:e2.

90. Richter $\mathbf{P}$, Hodge K, Stanfill S, et al. Surveillance of moist snuff: total nicotine, moisture, $\mathrm{pH}$, un-ionized nicotine, and tobacco-specific nitrosamines. Nicotine Tob Res 2008;10:1645-52.

91. Stepanov I, Jensen J, Hatsukami D, et al. New and traditional smokeless tobacco: comparison of toxicant and carcinogen levels. Nicotine Tob Res 2008:10:1773-82.

92. McNeill A, Bedi R, Islam S, et al. Levels of toxins in oral tobacco products in the UK. Tob Control 2006:15:64-7.

93. Stepanov I, Hecht SS, Ramakrishnan S, et al. Tobacco-specific nitrosamines in smokeless tobacco products marketed in India. Int J Cancer 2005;116:16-19. 
94. Idris AM, Nair J, Ohshima $\mathrm{H}$, et al. Unusually high levels of carcinogenic tobaccospecific nitrosamines in Sudan snuff (toombak). Carcinogenesis 1991;12:1115-18.

95. Luo J, Ye W, Zendehdel K, et al. Oral use of Swedish moist snuff (snus) and risk for cancer of the mouth, lung, and pancreas in male construction workers: a retrospective cohort study. Lancet 2007;369:2015-20.

96. Boffetta P, Aagnes B, Weiderpass E, et al. Smokeless tobacco use and risk of cancer of the pancreas and other organs. Int J Cancer 2005;114:992-5.

97. Boffetta $\mathbf{P}$, Straif K. Use of smokeless tobacco and risk of myocardial infarction and stroke: systematic review with meta-analysis. BMJ 2009;339:b3060.

98. Critchley JA, Unal B. Is smokeless tobacco a risk factor for coronary heart disease? A systematic review of epidemiological studies. Eur J Cardiovasc Prev Rehabil 2004;11:101-12.

99. Critchley JA, Unal B. Health effects associated with smokeless tobacco: a systematic review. Thorax 2003;58:435-43.

100. Boffetta P, Hecht S, Gray N, et al. Smokeless tobacco and cancer (review). Lancet Oncol 2008;9:667-75.

101. Gupta PC, Ray CS. Smokeless tobacco and health in India and South Asia. Respirology 2003;8:419-31.

102. Sapkota A, Gajalakshmi V, Jetly DH, et al. Smokeless tobacco and increased risk of hypopharyngeal and laryngeal cancers: a multicentric case-control study from India. Int J Cancer 2007;121:1793-8.

103. Gupta PC, Murti PR, Bhonsle RB. Epidemiology of cancer by tobacco products and the significance of TSNA. Crit Rev Toxicol 1996;26:183-98.

104. Foulds J, Furberg H. Is low-nicotine Marlboro snus really snus? Harm Reduct J 2008;5:9.

105. Henningfield JE, Fagerstrom KO. Swedish Match Company, Swedish snus and public health: a harm reduction experiment in progress? Tob Control

2001:10:253-7.

106. Fagerström K0, Schildt EB. Should the European Union lift the ban on snus? Evidence from the Swedish experience. Addiction 2003;98:1191-5.

107. Foulds J, Ramstrom L, Burke M, et al. Effect of smokeless tobacco (snus) on smoking and public health in Sweden. Tob Control 2003;12:349-59.

108. Rodu B, Stegmayr B, Nasic $S$, et al. Evolving patterns of tobacco use in northern Sweden. J Intern Med 2003;253:660-5.

109. Rodu B, Cole P. The burden of mortality from smoking: comparing Sweden with other countries in the European Union. Eur J Epidemiol 2004;19:129-31.

110. Tomar SL, Connolly GN, Wilkenfeld J, et al. Declining smoking in Sweden: is Swedish Match getting the credit for Swedish tobacco control's efforts? Tob Control 2003:12:368-71.

111. Bolinder G. Swedish snuff: a hazardous experiment when interpreting scientific data into public health ethics. Addiction 2003;98:1201-4.

112. Scientific Committee on Emerging and Newly Identified Health Risks (SCENIHR). Health Effects of Smokeless Tobacco Products. Brussels: Health and Consumer Protection Directorate-General, European Commission, 2008.

113. Henley SJ, Connell CJ, Richter P, et al. Tobacco-related disease mortality among men who switched from cigarettes to spit tobacco. Tob Control 2007;16:22-8.

114. Bates C, Fagerström K, Jarvis MJ, et al. European Union policy on smokeless tobacco: a statement in favour of evidence based regulation for public health. Tob Control 2003;12:360-7

115. Kozlowski LT. Effect of smokeless tobacco product marketing and use on population harm from tobacco use policy perspective for tobacco-risk reduction. Am J Prev Med 2007;33(6 Suppl):S379-86.

116. Hatsukami DK, Lemmonds C, Tomar SL. Smokeless tobacco use: harm reduction or induction approach? Prev Med 2004;38:309-17.

117. Tomar SL. Epidemiologic perspectives on smokeless tobacco marketing and population harm. Am J Prev Med 2007;33(6 Suppl):S387-97.

118. Phillips CV, Heavner KK. Smokeless tobacco: the epidemiology and politics of harm. Biomarkers 2009;14(Suppl 1):79-84.

119. Zeller M, Hatsukami D; Strategic Dialogue on Tobacco Harm Reduction Group. The strategic dialogue on tobacco harm reduction: a vision and blueprint for action in the US. Tob Control 2009;18:324-32.

120. Gartner CE, Hall WD, Chapman S, et al. Should the health community promote smokeless tobacco (snus) as a harm reduction measure? PLoS Med 2007:4:e185.

121. Tomar SL, Fox BJ, Severson HH. Is smokeless tobacco use an appropriate public health strategy for reducing societal harm from cigarette smoking? Int J Environ Res Public Health 2009;6:10-24.

122. Savitz DA, Meyer RE, Tanzer JM, et al. Public health implications of smokeless tobacco use as a harm reduction strategy. Am J Public Health 2006;96:1934-9.

123. Alderman J, Dollar KM, Kozlowski LT. Commentary: understanding the origins of anger, contempt, and disgust in public health policy disputes: applying moral psychology to harm reduction debates. J Public Health Policy 2010;31:1-16.

124. Henningfield JE, Rose CA, Giovino GA. Brave new world of tobacco disease prevention: promoting dual tobacco-product use? Am J Prev Med 2002;23:226-8.

125. Ramström LM, Foulds J. Role of snus in initiation and cessation of tobacco smoking in Sweden. Tob Control 2006;15:210-14.

126. Galanti MR, Rosendahl I, Wickholm S. The development of tobacco use in adolescence among "snus starters" and "cigarette starters": an analysis of the Swedish "BROMS" cohort. Nicotine Tob Res 2008;10:315-23.

127. Stenbeck M, Hagquist C, Rosén M. The association of snus and smoking behaviour: a cohort analysis of Swedish males in the 1990s. Addiction 2009;104:1579-85.

128. Tomar SL. Is use of smokeless tobacco a risk factor for cigarette smoking? The U.S. experience. Nicotine Tob Res 2003;5:561-9
129. Severson HH, Forrester KK, Biglan A. Use of smokeless tobacco is a risk factor for cigarette smoking. Nicotine Tob Res 2007;9:1331-7.

130. Haddock CK, Weg MV, DeBon M, et al. Evidence that smokeless tobacco use is a gateway for smoking initiation in young adult males. Prev Med 2001;32:262-7.

131. Timberlake DS, Huh J, Lakon CM. Use of propensity score matching in evaluating smokeless tobacco as a gateway to smoking. Nicotine Tob Res 2009;11:455-62.

132. Kozlowski LT, O'Connor RJ, Edwards BQ, et al. Most smokeless tobacco use is not a causal gateway to cigarettes: using order of product use to evaluate causation in a national US sample. Addiction 2003:98:1077-85.

133. O'Connor RJ, Flaherty BP, Quinio Edwards B, et al. Regular smokeless tobacco use is not a reliable predictor of smoking onset when psychosocial predictors are included in the model. Nicotine Tob Res 2003;5:535-43.

134. Rodu B, Cole P. Evidence against a gateway from smokeless tobacco use to smoking. Nicotine Tob Res 2010;12:530-4.

135. McClave-Regan AK, Berkowitz J. Smokers who are also using smokeless tobacco products in the US: a national assessment of characteristics, behaviours and beliefs of 'dual users'. Tob Control 2011;20:239-42.

136. Tomar SL, Alpert HR, Connolly GN. Patterns of dual use of cigarettes and smokeless tobacco among US males: findings from national surveys. Tob Control 2010:19:104-9

137. Mumford EA, Levy DT, Gitchell JG, et al. Tobacco control policies and the concurrent use of smokeless tobacco and cigarettes among men, 1992-2002. Nicotine Tob Res 2005; 7:891-900.

138. Wetter DW, McClure JB, de Moor C, et al. Concomitant use of cigarettes and smokeless tobacco: prevalence, correlates, and predictors of tobacco cessation. Prev Med 2002;34:638-48.

139. Kozlowski LT, Strasser AA, Giovino GA, et al. Applying the risk/use equilibrium: use medicinal nicotine now for harm reduction. Tob Control 2001:10:201-3.

140. Levy DT, Mumford EA, Cummings KM, et al. The relative risks of a low-nitrosamine smokeless tobacco product compared with smoking cigarettes: estimates of a panel of experts. Cancer Epidemiol Biomarkers Prev 2004;13:2035-42.

141. Levy DT, Mumford EA, Cummings KM, et al. The potential impact of a lownitrosamine smokeless tobacco product on cigarette smoking in the United States: estimates of a panel of experts. Addict Behav 2006;31:1190-200.

142. Gartner CE, Hall WD, Vos T, et al. Assessment of Swedish snus for tobacco harm reduction: an epidemiological modelling study. Lancet 2007;369:2010-14.

143. Mejia AB, Ling PM, Glantz SA. Quantifying the effects of promoting smokeless tobacco as a harm reduction strategy in the USA. Tob Control 2010:19:297-305

144. Stead LF, Perera R, Bullen C, et al. Nicotine replacement therapy for smoking cessation. Cochrane Database Syst Rev 2008; (1):CD000146.

145. Beard E, McNeill A, Aveyard P, et al. Use of nicotine replacement therapy for smoking reduction and during enforced temporary abstinence: a national survey of English smokers. Addiction 2011;106:197-204.

146. Tobacco Free Initiative. Two forms of nicotine replacement therapy chosen as WHO "Essential Medicines". 2009. http://www.who.int/tobacco/communications/ highlights/note nrt therapy/en/index.html

147. Gray N, Henningfield JE, Benowitz NL, et al. Toward a comprehensive long term nicotine policy. Tob Control 2005;14:161-5.

148. McNeill A, Foulds J, Bates C. Regulation of nicotine replacement therapies (NRT): a critique of current practice. Addiction 2001;96:1757-68.

149. Sweanor D. Regulatory imbalance between medicinal and non-medicinal nicotine Addiction 2000;95(Suppl 1):S25-8.

150. Warner KE, Slade J, Sweanor DT. The emerging market for long-term nicotine maintenance. JAMA 1997:278:1087-92.

151. Hammond D, Reid JL, Driezen P, et al. Smokers' use of nicotine replacement therapy for reasons other than stopping smoking: findings from the ITC Four Country Survey. Addiction 2008;103:1696-703. Erratum in: Addiction 2008; 103:2075

152. Levy DE, Thorndike AN, Biener L, et al. Use of nicotine replacement therapy to reduce or delay smoking but not to quit: prevalence and association with subsequent cessation efforts. Tob Control 2007;16:384-9.

153. Gerlach KK, Rohay JM, Gitchell JG, et al. Use of nicotine replacement therapy among never smokers in the 1999-2006 National Health and Nutrition Examination Surveys. Drug Alcohol Depend 2008;98:154-8.

154. Rainio SU, Huhtala HS, Rimpelä $\mathrm{AH}$. Use and acquisition of nicotine replacement therapy products among underaged adolescents after deregulation of the sales. Nicotine Tob Res 2010;12:870-3.

155. Horowitz DJ. Warning Letter to Bird's Hill Pharmacy Re: Nicotine Lollipops. Food and Drug Administration. 2002. http://www.fda.gov/foi/warning_letters/archive/ g3226d.htm

156. Horowitz DJ. Warning Letter to The Compounding Pharmacy Re: Nicotine Lollipops and Lip Balm. Food and Drug Administration. 2002. http://www.fda.gov/foi/ warning letters/archive/g3225d.htm

157. Schultz WB, Angulo CT, Cabe ME, et al. Petition for Regulation of SqF Garrett's Nicotine Water. 2001. http://news.findlaw.com/hdocs/docs/tobacco/ nich20fda121801pet.pdf

158. Pauly J, Li Q, Barry MB. Tobacco-free electronic cigarettes and cigars deliver nicotine and generate concern. Tob Control 2007;16:357.

159. Ayers JW, Ribisl KM, Brownstein JS. Tracking the rise in popularity of electronic nicotine delivery systems (electronic cigarettes) using search query surveillance. $A m$ J Prev Med 2011;40:448-53. 
160. Yamin CK, Bitton A, Bates DW. E-cigarettes: a rapidly growing Internet phenomenon. Ann Intern Med 2010;153:607-9.

161. Etter JF, Bullen C, Flouris $A D$, et al. Electronic nicotine delivery systems: a research agenda. Tob Control 2011:20:243-8.

162. Cahn Z, Siegel M. Electronic cigarettes as a harm reduction strategy for tobacco control: a step forward or a repeat of past mistakes? J Public Health Policy 2011;32:16-31.

163. Wollscheid KA, Kremzner ME. Electronic cigarettes: safety concerns and regulatory issues. Am J Health Syst Pharm 2009:66:1740-2.

164. Trtchounian A, Talbot P. Electronic nicotine delivery systems: is there a need for regulation? Tob Control 2011;20:47-52.

165. Vansickel AR, Cobb CO, Weaver MF, et al. A clinical laboratory model for evaluating the acute effects of electronic "cigarettes": nicotine delivery profile and cardiovascular and subjective effects. Cancer Epidemiol Biomarkers Prev 2010;19:1945-53.

166. Bullen C, McRobbie H, Thornley S, et al. Effect of an electronic nicotine delivery device (e cigarette) on desire to smoke and withdrawal, user preferences and nicotine delivery: randomised cross-over trial. Tob Control 2010;19:98-103.

167. Etter JF, Bullen C. Electronic cigarette: users profile, utilization, satisfaction and perceived efficacy. Addiction 2011:106:2017-28.

168. Siegel MB, Tanwar KL, Wood KS. Electronic cigarettes as a smoking-cessation tool results from an online survey. Am J Prev Med 2011;40:472-5.

169. Flouris AD, Oikonomou DN. Electronic cigarettes: miracle or menace? BM 2010;340:c311.

170. Timberlake DS, Pechmann C, Tran SY, et al. A content analysis of camel snus advertisements in print media. Nicotine Tob Res 2011;13:431-9.

171. Curry LE, Pederson LL, Stryker JE. The changing marketing of smokeless tobacco in magazine advertisements. Nicotine Tob Res 2011:13:540-7.

172. Mejia AB, Ling PM. Tobacco industry consumer research on smokeless tobacco users and product development. Am J Public Health 2010;100:78-87.

173. Noonan D. Exemptions for hookah bars in clean indoor air legislation: a public health concern. Public Health Nurs 2010;27:49-53.

174. Martinasek MP, McDermott RJ, Martini L. Waterpipe (hookah) tobacco smoking among youth. Curr Probl Pediatr Adolesc Health Care 2011:41:34-57.

175. Borland R, Wilson N, Fong GT, et al. Impact of graphic and text warnings on cigarette packs: findings from four countries over five years. Tob Control 2009; 18:358-64

176. Borland R, Yong HH, Wilson $\mathrm{N}$, et al. How reactions to cigarette packet health warnings influence quitting: findings from the ITC Four-Country survey. Addiction 2009;104:669-75.

177. Hammond D, Fong GT, Borland R, et al. Text and graphic warnings on cigarette packages: findings from the international tobacco control four country study. $\mathrm{Am} J$ Prev Med 2007;32:202-9.

178. Callery WE, Hammond D, O'Connor RJ, et al. The appeal of smokeless tobacco products among young canadian smokers: the impact of pictorial health warnings and relative risk messages. Nicotine Tob Res 2011;13:373-83.

179. Conference of the Parties. Partial guidelines for implementation of Articles 9 and 10 of the WHO Framework Convention on Tobacco Control (Regulation of the contents of tobacco products and Regulation of tobacco product disclosures). 2010. http://www.who.int/fctc/guidelines/Decisions9and10.pdf

180. WHO Study Group on Tobacco Product Regulation. Report on the Scientific Basis of Tobacco Product Regulation: Third Report of a WHO Study Group. WHO Technical Report Series 955. Geneva: WH0, 2009.

181. Hecht SS, Stepanov I, Hatsukami DK. Major tobacco companies have technology to reduce carcinogen levels but do not apply it to popular smokeless tobacco products. Tob Control 2011:20:443.

182. Ayo-Yusuf OA, Connolly GN. Applying toxicological risk assessment principles to constituents of smokeless tobacco products: implications for product regulation. Tob Control 2011;20:53-7.

183. Associated Press. Importer Tries to Get Around Clove Cigarette Ban. MSNBC, 2009. http://www.msnbc.msn.com/id/32723154/ns/business-consumer news/
184. Zajac A. FDA says tobacco law doesn't apply to two smokeless lozenges. Los Angeles Times 25 March 2011. http://articles.latimes.com/2011/mar/25/news/lapn-tobacco-lozenges-fda-20110325

185. Food and Drug Administration. Clarification About Dissolvable Tobacco Products http://www.fda.gov/TobaccoProducts/NewsEvents/ucm248801.htm

186. Deyton LR, Woodcock J. Regulation of E-Cigarettes and Other Tobacco Products Food and Drug Administration, 2011. http://www.fda.gov/NewsEvents/ PublicHealthFocus/ucm252360.htm

187. World Health Organization. WHO Technical Manual on Tobacco Tax Administration. Geneva: WHO, 2010.

188. Campaign for Tobacco-Free Kids. Closing weight-based tax loopholes for the new generation of low weight moist snuff smokeless tobacco products. 2011. http://www.tobaccofreekids.org/research/factsheets/pdf/0355.pdf

189. Licht AS, Hyland AJ, O'Connor RJ, et al. Socio-economic variation in price minimizing behaviors: findings from the International Tobacco Control (ITC) Four Country Survey. Int J Environ Res Public Health 2011:8:234-52.

190. Kesmodel D. Close, and it is a cigar. Wall St J 2010. http://online.wsj.com/article/ SB10001424052748703399404575505670223138144.html

191. Apuzzo M. Tobacco executives find tax loophole in child health law. The Boston Globe 18 November 2009. http://www.boston.com/news/health/articles/2009/11/ 18/tobacco_executives_quickly_find_tax_loophole/

192. Campaign for Tobacco-Free Kids. Creating federal tax equity among all tobacco products would increase federal revenues and promote public health. 2010. http:// www.tobaccofreekids.org/research/factsheets/pdf/0354.pdf

193. Carpenter CM, Connolly GN, Ayo-Yusuf OA, et al. Developing smokeless tobacco products for smokers: an examination of tobacco industry documents. Tob Control 2009;18:54-9.

194. Kozlowski LT. The determinants of tobacco use: cigarette smoking in the context of other forms of tobacco use. Can J Public Health 1982; 73:236-41.

195. Slade J. The tobacco epidemic: lessons from history. J Psychoactive Drugs 1992:24:99-109.

196. Bell K, McCullough L, Salmon A, et al. 'Every space is claimed': smokers' experiences of tobacco denormalisation. Sociol Health IIIn 2010;32:914-29.

197. Stuber J, Galea S, Link BG. Smoking and the emergence of a stigmatized social status. Soc Sci Med 2008;67:420-30.

198. Ritchie D, Amos A, Martin C. "But it just has that sort of feel about it, a leper" - stigma, smoke-free legislation and public health. Nicotine Tob Res 2010;12:622-9

199. Chapman S, Freeman B. Markers of the denormalisation of smoking and the tobacco industry. Tob Control 2008;17:25-31.

200. Noel JK, Rees VW, Connolly GN. Electronic cigarettes: a new 'tobacco' industry? Tob Control 2011:20:81.

201. Freeman B, Chapman S. Gone viral? Heard the buzz? A guide for public health practitioners and researchers on how Web 2.0 can subvert advertising restrictions and spread health information. $J$ Epidemiol Community Health 2008;62:778-82.

202. Rogers EM. Diffusion of Innovations. 5th edn. New York: Free Press, 2003.

203. Anderson SJ, Ling PM. "And they told two friends. and so on": RJ Reynolds' viral marketing of Eclipse and its potential to mislead the public. Tob Control 2008;17:222-9.

204. Freeman B, Chapman S. British American Tobacco on Facebook: undermining Article 13 of the global World Health Organization Framework Convention on Tobacco Control. Tob Control 2010;19:e1-9.

205. Elkin L, Thomson G, Wilson N. Connecting world youth with tobacco brands: YouTube and the internet policy vacuum on Web 2.0. Tob Control 2010;19:361-6.

206. Wackowski 0A, Lewis MJ, Delnevo CD. Qualitative analysis of Camel Snus' website message board-users' product perceptions, insights and online interactions. Tob Control 2011:20:e1.

207. Young D, Borland R. Conceptual challenges in the translation of research into practice: it's not just a matter of "communication". Translational Behavioral Medicine 2011:1:256-69. 